\title{
Current-use and Organochlorine Pesticides and Polychlorinated Biphenyls in the Biodegradable Fraction of Source Separated Household Waste, Compost and Anaerobic Digestate
}

\author{
Anna Hellström, Marie-Louise Nilsson and Henrik Kylin
}

\section{Linköping University Post Print}

N.B.: When citing this work, cite the original article.

The original publication is available at www.springerlink.com:

Anna Hellström, Marie-Louise Nilsson and Henrik Kylin, Current-use and Organochlorine Pesticides and Polychlorinated Biphenyls in the Biodegradable Fraction of Source Separated Household Waste, Compost and Anaerobic Digestate, 2011, Bulletin of Environmental Contamination and Toxicology, (86), 1, 60-64.

http://dx.doi.org/10.1007/s00128-010-0147-1

Copyright: Springer Verlag (Germany)

http://www.springerlink.com/

Postprint available at: Linköping University Electronic Press

http://urn.kb.se/resolve?urn=urn:nbn:se:liu:diva-66442 


\title{
Current-use and Organochlorine Pesticides and Polychlorinated Biphenyls in the Biodegradable Fraction of Source Separated Household Waste, Compost, and Anaerobic Digestate
}

\author{
Marie-Louise Nilsson, Anna Hellström, Henrik Kylin ${ }^{1 *}$ \\ Department of Aquatic Sciences and Assessment, Swedish University of Agricultural Sciences, \\ P.O. Box 7050, SE-750 07 Uppsala, Sweden
}

\begin{abstract}
Several current-use ( $\leq 80 \mathrm{ng} \mathrm{g}^{-1}$ dry weight) and organochlorine pesticides ( $\leq 15 \mathrm{ng} \mathrm{g}^{-1}$ dry weight) and polychlorinated biphenyls ( $\leq 18 \mathrm{ng} \mathrm{g}^{-1}$ dry weight) were found in the biodegradable fraction of source separated household waste, compost, and/or anaerobic digestate. The degradation rates of individual compounds differ depending on the treatment. Dieldrin and pentachloroaniline, e.g., degrade more rapidly than the waste is mineralized and accumulates in the products after all treatments. Many organochlorines degrade at the same rate as the waste and have the same concentrations in the waste and products. Chlorpyrifos degrades slower than the waste and accumulates in all products and ethion during anaerobic digestion. The polychlorinated biphenyls and some pesticides show different degradations rates relative the waste during different processes. Understanding the degradation of the contaminants under different conditions is necessary to develop quality criteria for the use of compost and digestate.
\end{abstract}

Key words: Organic waste; Composting; Mesophilic digestion; Thermophilic digestion; Recirculation

In many European countries, composting and/or anaerobic digestion are increasingly important methods to dispose of the biodegradable fraction of household waste (Brändli 2006). Not only is it a means of reducing the amount of waste that needs to be deposited or incinerated, but it is also a potential means of recycling nutrients from urban areas to agriculture. However, to recycle the compost or digestate it is necessary to ensure that these products do not contain too much toxic compounds that may accumulate in the soil or in the crops. Therefore, it is necessary to define quality criteria for compost and digestate to develop a market for these products (Nilsson 2000). Such quality criteria will have to contain regulations on, e.g., the concentrations of various contaminants. It is, therefore, necessary to understand the fate of contaminants during composting and anaerobic digestion to find relevant and safe use for the resulting products.

Among possible organic contaminants in compost or digestate most interest has been given persistent organic pollutants (POPs) and priority pollutants such as polycyclic aromatic hydrocarbons (Brändli et al. 2005, 2007a, 2007b), while relatively little attention has been given the current-use pesticides (CUPs). This is possibly due to the assumption that CUPs will degrade more rapidly than POPs. However, very few investigations that support this assumption have been performed. When CUPs have been investigated many have been found in both compost and digestate (Nilsson 2000, Brändli et al. 2007c). However, whatever contaminants that have been studied, the analyses have in most cases been restricted to the compost and/or digestate without connecting the concentrations in the products with the concentrations in the feedstock.

\footnotetext{
${ }^{1}$ Corresponding author, e-mail: henrik.kylin@vatten.slu.se, fax: +4618673156, phone +4670833619
} 
To develop relevant quality criteria it is necessary to understand the connection between what is found in the feedstock and the products (Nilsson 2000). To gain this type of understanding we screened the biodegradable fraction of source separated household waste and the compost and mesophilic and thermophilic anaerobic digestate produced with this feedstock for selected CUPs and POPs.

\section{Materials and Methods}

The biodegradable fraction of source separated household waste was sampled at the municipal composting plant at Hovgården, Uppsala. The material was collected in February 1995, sorted, and characterised as described by Eklind et al. (1997). Further characterisation of the material is given in Nilsson et al. (2000). The samples of compost and anaerobic digestate were from this feedstock with composting and digestion conditions as described by Nilsson et al. (2000). In short, mesophilic $\left(37^{\circ} \mathrm{C}\right)$ and thermophilic $\left(55^{\circ} \mathrm{C}\right)$ anaerobic digesters were operated semicontinuously (small amounts of feedstock added daily) with a hydraulic retention time of 30 and 19 days respectively. Composting was performed in isolated bins (Joraform, Mjölby Sweden); the compost was mature after 5 months.

Pesticide or HPLC grade solvents were acetone, cyclohexane, dichloromethane, and nhexane (Lab-Scan Analytical Science, Dublin, Ireland), 2-propanol, toluene, and n-heptane (Merck-Eurolabs, Spånga, Sweden), and iso-octane (Rathburn Chemicals, Walkerburn, Scotland). Authentic pesticide standards (Dr. Ehrenstorfer, Augsburg, Germany) in acetone or other suitable solvent were prepared $(0.15-11.4 \mu \mathrm{g} / \mathrm{mL})$ from stock solutions or pure compounds (98-100\% purity). Other chemicals were analytical grade sulphuric acid, anhydrous sodium sulphate (Merck-Eurolabs) heated to $550^{\circ} \mathrm{C}>8 \mathrm{~h}$ and stored in a desiccator, and hydromatrix (Varian Sample Preparation Products, Harbor City, CA, USA). Silica gel 60 (70-230 mesh, Merck-Eurolabs) was washed with dichloromethane, dried at $130{ }^{\circ} \mathrm{C}(\geq 5 \mathrm{~h})$, cooled in a desiccator and deactivated with deionised water $(1.5 \%, \mathrm{w} / \mathrm{w})$ on a shaking table $(\geq 2.5 \mathrm{~h})$ and then stored under n-hexane.

The sample (40 g, app. 12 g dry substance) was mixed and ground with hydromatrix (5 g) in a mortar and extracted with acetone:dichloromethane 3:1 in a Soxhlet apparatus over night. The extract was washed with water $(50 \mathrm{~mL})$ saturated with sodium chloride solution in a separatory funnel transferred to an Erlenmeyer flask and dried with sodium sulphate. The extract was filtrated into a round bottomed flask and concentrated on a rotary evaporator $\left(40^{\circ} \mathrm{C}\right)$ and filtered (0.45 $\mu \mathrm{m}$ filter disc, Acrodisc PTFE, Gelman Sciences, Ann Arbor, MI, USA).

To enable screening for a large number of CUPs and organochlorine compounds the samples were treated according to Specht and Tillkes (1985) affording six fraction in which different pesticides are found. The method was calibrated and checked for reproducibility by adding the analytes to the sample matrices at twice and five times the expected limit of quantification. The limit of detection (LOD) was set to three times the background noise and the limit of quantification (LOQ) to three times the LOD (Table 1). For sample types where the detection frequency of an analyte was more than $80 \%$, the concentration of non-detects were set to half the LOD and traces (between the LOD and LOQ) to half the LOQ when calculating the mean and standard deviation.

Size exclusion chromatography (SEC) was performed using Bio Beads SX-3 gel (200-400 mesh, Bio-Rad Laboratories, Hercules, CA, USA) in an SR 25/50 column (i.d. $=2.5 \mathrm{~cm}$ Pharmacia \& Upjohn, Uppsala, Sweden), with a type NYC-13D3 pump (Bodine Electric Company, Chicago, USA) with cyclohexane:dichloromethane (1:1, v:v, $5.0 \mathrm{~mL} / \mathrm{min})$ as eluent. The eluent was collected from 16 min, using ethion and diazinon as cut-off indicators. The solvent volume was reduced on a rotary evaporator to approximately $0.5 \mathrm{~mL}$. The remaining solution was transferred to a 5-mL graduated test tube, n-heptane added and the remaining SEC 
solvent was evaporated under a gentle stream of nitrogen without evaporating to dryness. The final volume was adjusted to $1 \mathrm{~mL}$ with $\mathrm{n}$-heptane.

Adsorption chromatography was performed on deactivated silica gel (1 g slurry in n-hexane) packed in a glass column (10 mm i.d.) with anhydrous sodium sulphate $(0.7-1 \mathrm{~cm})$ on top. The silica column was washed with n-hexane after which the n-heptane extract was loaded onto the column and eluted with n-hexane $(8 \mathrm{~mL})$. The column was then successively eluted with nhexane:toluene 65:35, toluene, toluene:acetone 95:5, toluene:acetone $80: 20$, acetone (8 mL each). To each of the six fractions bromophosethyl was added $(0.18 \mu \mathrm{g})$ as internal standard and the volume adjusted to $1 \mathrm{~mL}$.

Gas chromatography-mass spectrometry (GC-MS) was performed on an HP-5890 gas chromatograph with an autosampler and a Trio-1 quadrupole mass spectrometer (VG instruments, Manchester, UK) using either electron ionisation (EI, $70 \mathrm{eV}$ ) or negative chemical ionisation (NCI) with methane as ionization gas. Column: HP-1 fused silica (25 m, $0.25 \mathrm{~mm}$ i.d., $0.25 \mu \mathrm{m}$ df, Hewlett-Packard, Wilmington, Delaware, USA). Temperature programme $90^{\circ} \mathrm{C}$ for $1 \mathrm{~min}, 30^{\circ} \mathrm{C} / \mathrm{min}$ to $220^{\circ} \mathrm{C}, 4^{\circ} \mathrm{C} / \mathrm{min}$ to $300^{\circ} \mathrm{C}$ isothermal for $5 \mathrm{~min}$; carrier gas helium', injection volume $1 \mu \mathrm{l}$. All GC-MS analyses were performed in selected ion monitoring using the fragments presented in Table 1.

After determination of CUPs, fractions 1-2 were pooled and passed through a column of concentrated sulphuric acid:silica gel (1:2, w:w) in a Pasteur pipette for the analysis of acid resistant organochlorines (Kylin et al. 1996). The acid resistant organochlorines were determined using GC with dual electron capture detectors (ECD). Two columns of different polarity (CP-Sil 5 CB and CP-Sil 19 CB, 30 m, 0.25 mm i.d., $0.2 \mu \mathrm{m}$ df, Chrompack, Middelburg, the Netherlands) were inserted in the same injector, but different detectors. The injector was kept at $260^{\circ} \mathrm{C}$, splitless injection, split opened after one min., detector temperature $300^{\circ} \mathrm{C}$.

\section{Results and Discussion}

Twenty pesticides, three degradation products, and twelve compounds of industrial origin were positively identified in one or more of the feedstock, compost, or mesophilic or thermophilic digestate (Table 2). Many CUPs are substantially less stable than the POPs during the work-up process, making their quantification in complex matrices challenging. This is problematic as some CUPs have ecotoxic effects at levels below where they are normally detected (Cromentuijn et al. 2000). To obtain more relevant detection limits we used a fractionation system originally developed to detect a large number of pesticides in fruits and vegetables (Specht and Tillkes 1985).

For practical reasons we limited the number of pesticides we screened for to those frequently found in vegetables and fruits in Sweden (Swedish Food Administration 2010). As a whole the samples were screened for the presence of 34 CUPs/degradation products, 10 organochlorine pesticides/degradation products, hexachlorobenzene (HCB), and 11 PCB congeners, but for brevity only those compounds positively identified are included in Tables 1 and 2. Most of the CUPs identified are used to protect a wide variety of fruits and vegetables (Swedish Chemicals Agency 2010). Dieldrin, endrin and DDT are persistent organochlorine pesticides banned in banned for most uses (Stockholm Convention 2010). However, they are still found in many parts of the world due to volatilisation and aerial transport to remote areas and accumulate at higher trophic levels in food chains. The presence of POPs in the tested materials may be due to deposition to fruits and vegetables, but more probably to accumulation in fish and meat in the waste.

The majority of the CUPs detected are not registered for use in Sweden, reflecting that most fruits and vegetables consumed in Sweden during February (when this material was collected) are of foreign origin. The two exceptions are metalaxyl and tetradifon. Metalaxyl is a fungicide 
in Sweden used in the cultivation of potatoes and onions (not on the edible parts). But as the total use of these compounds in Sweden is restricted, less than $200 \mathrm{~kg}$ nationwide (Swedish Chemicals Agency 2010), these residues are probably also due to imported fruits and vegetables.

The presence of traces of dichlobenil and its degradation product 2,6-dichlorobenzamide in some compost and digestate samples is puzzling. Dichlobenil is a soil herbicide, no longer used in Sweden, and it is unlikely that it would be present in the original waste material since it would have killed any vegetables where it had been used. And since neither compound bioaccumulates, they would not be present in waste of animal origin. Most likely, the equipment used to handle the material at Hovgården also has been used to excavate contaminated soils in other parts of the city. Such soils are common in Uppsala (Wallman 2000).

In spite of the high variability in the material, four major contaminant fate scenarios are indicated. The first is that a compound present in the feedstock is degraded more rapidly than the feedstock is mineralized, i.e., the concentrations are lower in the products than in the feedstock. Examples of this are dieldrin and pentachloroaniline.

The second fate scenario is that a contaminant is degraded approximately at the same rate and the feedstock is mineralized leading to similar concentrations in the feedstock and products. Examples are DDE (1,1-dichloro-bis(4-chlorophenyl)-2,2-ethene), the endosulfans, HCB (hexachlorobenzene), several of the polychlorinated biphenyl (PCB) congeners, tetradifon, and vinclozoline.

In the third scenario the feedstock is mineralized more rapidly than the contaminants are degraded. An example is chlorpyrifos that was not detected in the feedstock, but all three products.

Finally, some compounds degrade at different rates during the different processes. Ethion was not detected in the feedstock or the compost, but in both the digestates. Reversely, DDT (1,1,1-trichloro-bis(4-chlorophenyl)-2,2-ethane), some of the PCB congeners, and quintozene were detected in the feedstock and compost, but not the digestates. Metalaxyl was only detected in the compost and thermophilic digestate, while phosalone was detected only in the mesophilic digestate.

The refractive nature of several CUPs may seem unexpected. Compounds such as chlorpyrifos and ethion contain phosphate esters and should be fairly easily hydrolysed.

However, Brändli et al. (2007c) also found several CUPs in similar matrices, although they did not present data from the feedstocks. To further emphasize the variable degradation rates and sometimes refractive nature of CUPs, some have degradation half-lives of more than a year in manure while others degrade rapidly (Kylin et al. 2007). During the 1980s and 1990s the Swedish Board of Agriculture recommended the disposal of leftover CUPs in liquid manure tanks. Because of the longevity of several CUPs, this practise resulted in crop damage (Kylin et al. 2007). It has also been shown that clopyralid is refractive during the composting process why restrictions on how compost from grass clippings containing clopyralid may be used have been suggested (Miltner et al. 2003). The combined impression of these studies is that there is a need for a better understanding of the fate of various contaminants during composting and anaerobic digestion if an efficient system to recycle these materials is to be developed. More studies especially focusing on CUPs are necessary as some, obviously, are more refractive than expected.

Acknowledgements This work was carried out within the research programme "Biological Waste in Circulation Between Urban and Rural Areas" funded by the Faculty of Agriculture, Horticulture and Landscape Planning, Swedish University of Agricultural Sciences. 


\section{References}

Brändli RC, Bucheli TD, Kupper T, Furrer R, Stadelmann FX, Tarradellas J (2005) Persistent Organic Pollutants in Source-Separated Compost and Its Feedstock Materials -A Review of Field Studies. J Environ Qual 34:735-760

Brändli RC (2006) Organic Pollutants in Compost and Digestate in Switzerland. Thesis, École Polytechnique Fédérale de Lausanne, Switzerland

Brändli RC, Bucheli TD, Kupper T, Mayer J, Stadelmann FX, Tarradellas J (2007a) Fate of PCBs, PAHs and their source characteristic ratios during composting and digestion of source-separated organic waste in full-scale plants. Environ Pollut 148:520-528

Brändli RC, Bucheli TD, Kupper T, Furrer R, Stahel WA, Stadelmann FX, Tarradellas J (2007b) Organic pollutants in compost and digestate. Part 1. Polychlorinated biphenyls, polycyclic aromatic hydrocarbons and molecular markers. J Environ Monit 9:456-464

Brändli RC, Kupper T, Bucheli TD, Zennegg M, Huber S, Ortelli D, Müller J, Schaffner C, Iozza S, Stadelmann FX, Tarradellas J (2007c) Organic pollutants in compost and digestate.

Part 2. Polychlorinated dibenzo-p-dioxins, and -furans, dioxin-like polychlorinated

biphenyls, brominated flame retardants, perfluorinated alkyl substances, pesticides, and other compounds. J Environ Monit 9:465-472

Crommentuijn T, Sijm D, de Bruijn J, van Leeuwen K, van de Plassche E (2000) Maximum permissible and negligible concentrations for some organic substances and pesticides. $\mathrm{J}$ Environ Manag 58:297-312

Eklind Y, Beck-Friis B, Bengtsson S, Ejlertsson J, Kirchmann H, Mathisen B, Nordkvist E, Sonesson U, Svensson BH, Torstensson L (1997) Chemical Characterization of SourceSeparated Organic Household Wasts. Swedish J Agric Res 27:167-178

Kylin H, Nordstrand E, Sjödin A, Jensen S (1996) Deternmination of chlorinated pesticides and PCB in pine needles - improved method thr the monitoring of airborne organochlorine pollutants. Fresenius' J Anal Chem 356:62-69

Kylin H, Torstensson L, Ramberg Å, Volkova L, Sundin P (2007) Crop damage may occur after herbicide disposal in manure - a preliminary study. Acta Agric Scandinavica, Sect B, Soil Plant Sci 57:243-247

Miltner E, Bary A, Cogger C (2003) Clopyralid and compost: Formulation and mowing effects on herbicide content of grass clippings. Compost Sci Util 11:289-299

Nilsson M-L (2000) Occurrence and fate of organic contaminants in wastes. Thesis, Swedish University of Agricultural Sciences, Uppsala

Nilsson M-L, Kylin H, Sundin P (2000) Major extractable Organic Compounds in the Biologically Degradable Fraction of Fresh, Composted and Anaerobically Digested Household Waste. Acta Agric Scandinavica, Sect B, Soil Plant Sci 50:57-65.

Specht W, Tillkes M (1985) Gas-chromatographische Bestimmung von Rückständen an Pflanzenbehandlungsmitteln nach Clean-up über Gelchromatographie und Mini-KieselgelSäulen-Chromatographie. Fresenius Z Anal Chem 322:445-455

Stockholm Convention (2010) http://chm.pops.int/default.aspx. Accessed 15 June 2010

Swedish Chemicals Agency (2010) http://www.kemi.se. Pesticide registry. Accessed 15 June 2010

Swedish Food Administration (2010) http://www.slv.se/sv/Sjalvservice/Rapporter/Bekampningsmedel-/. Accessed 15 June 2010

Wallman K (2000) Atrazine and dichlorobenzamide residues in the ground water of Uppsala the source of the contamination. Dept Environ Assess, Swedish Univ Agric Sci, Report 2000:7, Uppsala 
Table 1 Limit of detection, ionization method and fragments monitored for the for the GC-MS detection of the various CUPs. Organochlorines were detected with GC-ECD.

\begin{tabular}{|c|c|c|c|}
\hline Compound & $\begin{array}{c}\text { LOD } \\
\text { ng/g dr.w. }\end{array}$ & $\begin{array}{c}\text { Detection } \\
\text { Technique }\end{array}$ & $\begin{array}{c}\text { Fragments } \\
\text { monitored }(\mathrm{m} / \mathrm{z})\end{array}$ \\
\hline Bromopropylate & 0.2 & NCI & $426,428,430$ \\
\hline Chlorpropham & 50 & EI & $127,171,213$ \\
\hline Chlorpyrifos & 0.5 & EI & $97,197,314$ \\
\hline Chlorothalonil & 0.5 & EI & 264, 266, 268 \\
\hline $\mathrm{DDE}$ & 0.05 & ECD & \\
\hline DDT & 0.05 & ECD & \\
\hline Dichlobenil & 0.5 & NCI & $171,173,175$ \\
\hline 2,6-dichlorobenzamide & 0.8 & EI & $173,175,189$ \\
\hline Dieldrin & 0.08 & NCI & 235, 237, 239 \\
\hline Diphenylamine & 2 & EI & $83,168,169$ \\
\hline Endosulfan- $\alpha$ & 0.08 & NCI & 404, 406, 408 \\
\hline Endosulfan- $\beta$ & 0.1 & NCI & 404, 406, 408 \\
\hline Endosulfan-sulphate & 0.08 & NCI & 384, 386, 388, \\
\hline Endrin & 0.1 & $\mathrm{NCI}$ & 237, 235, 239 \\
\hline Ethion & 0.7 & EI & $153,231,384$ \\
\hline $\mathrm{HCB}$ & 0.08 & ECD & \\
\hline Lindane & 0.08 & ECD & \\
\hline Metalaxyl & 0.1 & EI & 160, 206249 \\
\hline Parathion & 0.05 & EI & 109, 139, 291 \\
\hline PCB $31+28$ & 0.1 & ECD & \\
\hline PCB 52 & 0.1 & ECD & \\
\hline PCB 101 & 0.05 & ECD & \\
\hline PCB 105 & 0.05 & ECD & \\
\hline PCB 118 & 0.05 & ECD & \\
\hline PCB 128 & 0.05 & ECD & \\
\hline PCB 138 & 0.05 & ECD & \\
\hline PCB 153 & 0.05 & ECD & \\
\hline PCB 156 & 0.05 & ECD & \\
\hline PCB 170 & 0.01 & ECD & \\
\hline PCB 180 & 0.01 & ECD & \\
\hline Pentachloroanilin & 0.03 & EI & 263, 265, 267 \\
\hline Phosalone & 0.5 & NCI & 185, 186, 187 \\
\hline Quintozene & 0.08 & NCI & 249, 263, 269 \\
\hline Tetradifon & 0.01 & $\mathrm{NCI}$ & 318, 320, 322 \\
\hline Vinclozoline & 0.1 & EI & 198, 212,285 \\
\hline
\end{tabular}


Table 2 Concentrations on a dry weight basis (range, mean, and standard deviation) of the contaminants in the four materials.

\begin{tabular}{|c|c|c|c|c|c|c|c|c|c|c|c|c|}
\hline \multirow[t]{2}{*}{ Compound } & \multicolumn{3}{|c|}{$\begin{array}{l}\text { Waste }(n=9) \\
\text { ng g }^{-1} \text { dr.w. }\end{array}$} & \multicolumn{3}{|c|}{$\begin{array}{l}\text { Compost (n=5). } \\
\text { ng g g }^{-1} \text { dr.w. }\end{array}$} & \multicolumn{3}{|c|}{$\begin{array}{l}\text { Mesophilic digestate }(\mathrm{n}=4) \\
\text { ng g }^{-1} \text { dr.w. }\end{array}$} & \multicolumn{3}{|c|}{$\begin{array}{l}\text { Thermophilic digestate }(\mathrm{n}=5) \\
\text { ng g }^{-1} \text { dr.w. }\end{array}$} \\
\hline & Range & Mean & sd & Range & Mean & sd & Range & Mean & sd & Range & Mean & sd \\
\hline Bromopropylate & ND*-67 & 21.6 & 25.5 & $12-79$ & 42 & 26 & $15-21$ & 13.8 & 9.3 & $42-84$ & 57 & 18 \\
\hline Chlorpropham & $\operatorname{tr} \dagger(5) \ddagger$ & - & - & ND & - & - & ND & - & - & ND & - & - \\
\hline Chlorpyrifos & ND & - & - & $3-3.4$ & 3.2 & 0.2 & $13-23$ & 18 & 4.1 & $13-28$ & 21.6 & 6.3 \\
\hline Chlorothalonil & $\operatorname{tr}(1)$ & - & - & ND-2.2 & 1,4 & 1,0 & ND & - & - & ND & - & - \\
\hline DDE & $0.9-2.5$ & 1.5 & 0.5 & $1.6-2.3$ & 1.9 & 0.3 & ND-4.2 & 2.8 & 1.9 & $1-5.9$ & 2.7 & 1.9 \\
\hline DDT & ND-0.9 & 0.7 & 0.3 & ND-4.5 & 2.6 & 1.6 & ND & - & - & ND & - & - \\
\hline Dichlobenil & ND & - & - & $\operatorname{tr}(2)$ & - & - & $\operatorname{tr}(4)$ & - & - & $\operatorname{tr}(5)$ & - & - \\
\hline 2,6-dichlorobenzamide & ND & - & - & ND & - & - & $\operatorname{tr}(4)$ & - & - & $\operatorname{tr}(5)$ & - & - \\
\hline Dieldrin & $0.5-15$ & 3.4 & 4.8 & ND & - & - & ND & - & - & ND & - & - \\
\hline Diphenylamine & $\operatorname{tr}(6)$ & - & - & ND & - & - & ND & - & - & ND & - & - \\
\hline Endosulfan- $\alpha$ & $1-14$ & 5.2 & 4.1 & $3-5.8$ & 4.6 & 1.1 & $1-3.1$ & 2.4 & 1.4 & $1.4-2.5$ & 1.7 & 0.4 \\
\hline Endosulfan- $\beta$ & $2.8-4.7$ & 3.9 & 1.0 & $2.2-5.7$ & 4.8 & 1.5 & ND-5.2 & 2.4 & 1.3 & ND-1.4 & 0.7 & 0.5 \\
\hline Endosulfan-sulphate & $0.3-18$ & 8.6 & 6.8 & $10-14$ & 12.7 & 1.4 & $2-5.7$ & 3.2 & 1.6 & $0.6-1.9$ & 1.4 & 0.5 \\
\hline Endrin & $\operatorname{tr}(5)$ & - & - & ND & - & - & ND & - & - & ND & - & - \\
\hline Ethion & ND & - & - & $\operatorname{tr}(1)$ & - & - & $3.6-7$ & 6.0 & 1.7 & $1.7-5.4$ & 3.7 & 2.0 \\
\hline НCB & $0.4-0.8$ & 0.6 & 0.1 & $0.5-0.8$ & 0.6 & 0.1 & ND-0.8 & 0.5 & 0.3 & ND-0.8 & 0.4 & 0.4 \\
\hline Lindane & ND & - & - & ND-1.5 & 1.2 & $0.6-$ & ND & - & - & ND & - & - \\
\hline Metalaxyl & ND & - & - & 0.6-2 & 1.7 & 0.6 & ND & - & - & $0.3-2$ & 0.85 & 0.83 \\
\hline Parathion & $\operatorname{tr}(2)$ & - & - & ND & - & - & ND & - & - & ND & - & - \\
\hline PCB 31+28 & ND-3.8 & 2.3 & 1.3 & $10-30$ & 1.5 & 0.4 & ND & - & - & ND & - & - \\
\hline PCB 52 & $1.3-2.1$ & 1.4 & 0.6 & $1.2-2.2$ & 1.7 & 0.4 & $0.9-2.1$ & 1.5 & 0.5 & $1.0-1.9$ & 1.4 & 0.4 \\
\hline PCB 101 & $1.7-4.9$ & 2.4 & 1.4 & $1.9-2.7$ & 2.3 & 0.3 & $1.4-2.5$ & 2.4 & 0.8 & $1.6-2.9$ & 2.3 & 0.5 \\
\hline PCB 105 & tr-1.7 & 1.1 & 0.5 & $1.1-1.4$ & 1.2 & 0.2 & ND & - & - & ND & - & - \\
\hline PCB 118 & $1.7-4.4$ & 2.4 & 1.3 & $2.1-2.7$ & 2.4 & 0.3 & $1.6-3.9$ & 2.8 & 1.0 & $2.1-3.2$ & 2.7 & 0.5 \\
\hline PCB 128 & $\operatorname{tr}-1.9$ & 0.8 & 0.6 & $0.4-0.5$ & 0.4 & 0.1 & ND & - & - & $0-0.7$ & 0.4 & 0.3 \\
\hline
\end{tabular}




\begin{tabular}{l|ccc|ccc|ccc|cc|c} 
PCB 138 & $2.2-18$ & 5.0 & 5.6 & $2.9-3.8$ & 3.3 & 0.4 & $1.6-4.3$ & 3.2 & 1.3 & $0.7-3.8$ & 2.7 & 1.2 \\
PCB 153 & $1.7-20$ & 4.4 & 5.9 & $2.4-3.2$ & 2.8 & 0.3 & $1.1-2.5$ & 2.2 & 1.1 & $1.0-3.3$ & 2.6 & 1.0 \\
PCB 156 & $\operatorname{tr}-1.8$ & 0.5 & 0.7 & $0.2-0.3$ & 0.3 & 0.0 & ND & & & $0-0.4$ & 0.3 & 0.1 \\
PCB 170 & $0.3-6.7$ & 1.9 & 2.6 & ND-0.3 & 0.2 & 0.1 & ND-0.3 & 0.1 & 0.1 & $0-0.2$ & 0.1 & 0.1 \\
PCB 180 & $0.3-14$ & 2.2 & 4.6 & $0.2-0.8$ & 0.6 & 0.3 & ND-0.8 & 2.4 & 4.0 & $0.3-0.7$ & 0.5 & 0.2 \\
Pentachloroaniline & $28-42$ & 36 & 17 & $0.7-1.2$ & 0.9 & 0.002 & $0.09-1.5$ & 0.7 & 0.3 & $1-2.2$ & 1.6 & 0.3 \\
Phosalone & $\operatorname{tr}(5)$ & - & - & ND & - & - & $0.6-1.8$ & 1.0 & 0.5 & ND & - & - \\
Quintozene & $0.1-2$ & 0.7 & 0.6 & $0.8-1.2$ & 0.96 & 0.15 & ND & - & - & ND & - & - \\
Tetradifon & $4-46$ & 21.0 & 15.9 & $1.3-13.1$ & 4.0 & 5.1 & $0.06-1.3$ & 3.5 & 5.6 & $5.7-15$ & 10.1 & 3.6 \\
Vinclozoline & $3-36$ & 14.1 & 13.0 & $2.4-10.4$ & 5.1 & 3.1 & $2.2-6.7$ & 4.5 & 2.3 & $1.6-12$ & 4.9 & 4.3 \\
\hline
\end{tabular}

*ND = Not detected

$\dagger \mathrm{tr}=$ trace concentrations (concentration between the limit of detection and limit of quantification)

¥When concentrations varied between nd and tr the number of samples with trace concentrations are given in parenthesis. 